\title{
Analysis on Local Compression Bearing Capacity of Deep Reinforced Concrete Corbels Constrained by Prestress
}

\author{
YIN Xinsheng ${ }^{1, a}$, LIU Yang ${ }^{1, b}$, CAI Jingwei ${ }^{2, c}$ \\ ${ }^{1}$ Green Building Technology Engineering Center , Jilin Jianzhu University , Changchun130118 , \\ China \\ ${ }^{2}$ Harbin Institute of Technology,Harbin150001,China

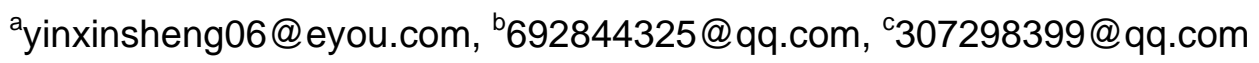

Keywords: prestress, local compression, deep corbel, ultimate bearing capacity

Abstract. Through the calculation and analysis on the stress state of deep corbel under local compression, reinforce deep corbel by external prestressing form. According to the calculation results, find the difference between the stress distribution constrained by prestress and that of normal working state, analysis on the influence of different position on the ultimate bearing capacity. The working mechanism of deep corbel and ordinary corbel are basically the same. The concrete at the middle area of corbel constrained by prestress strongly, Its ultimate bearing capacity and crack resistance increased significantly. With the position of prestressed constraints changing, the ultimate bearing capacity of deep corbel also changes. The ideal constrained position is located in the central of deep corbel.

\section{Introduction}

With the development of China's heavy industry, require to improve the bearing capacity of the main load-bearing member of the industrial plant, ordinary reinforced concrete corbel column has been difficult to adapt to the requirements of bearing capacity of large tonnage crane. To meet the needs of industrialization and the large tonnage crane lifting the weight, deep bracket gradually began to replace the ordinary is applied to building structure. Deep corbel bracket refers to the middle of the column extended area, usually extended area $1 \sim 1.5$ meters in height.

Combined with engineering examples, explore the stress distribution of deep bracket under

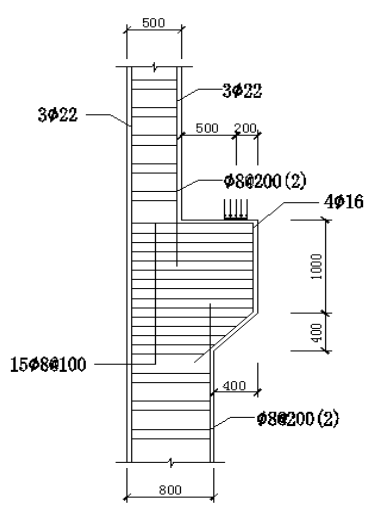

Fig-1 corbel with rebar

normal working state through the finite element analysis software ABAQUS to analyze the deep corbel bracket under the partial pressure condition, Based on the deep corbels were strengthened by external prestressing explore the stress state of the prestressed constraints and analysis of the improvement of ultimate bearing capacity by changing the size of the applied prestress and the influence of ultimate bearing capacity by changing of the applied stress.

\section{Model establishment}

\section{Brief introduction of model examples}

A single storey industrial building deep column bracket reinforcement and size as shown below. 
Concrete strength grade is C40, the bracket column thickness is $400 \mathrm{~mm}$, protective layer thickness is $40 \mathrm{~mm}$, steel bar using HRB400 grade, the load area is $200 \mathrm{x} 400 \mathrm{~mm}$ of the rectangular area. The prestressed nominal diameter is $15.2 \mathrm{~mm}$, and the area of prestressed steel strand is $139 \mathrm{~mm}^{2}$, end anchorage of steel plate by $600 \times 400 \mathrm{~mm}, 600 \times 600 \mathrm{~mm}, 600 \times 800 \mathrm{~mm}, 600 \times 1000 \mathrm{~mm}$, the thickness is $20 \mathrm{~mm}$.

\section{Model material properties and process}

This paper uses finite element analysis software ABAQUS analysis, calculation model based on the CAE function of the establishment. 3 dimensional solid element is established by concrete and steel plate, 3 dimensional line unit built with reinforced and prestressed steel strand, and by specifying the cross-sectional area to achieve the definition of section properties, specific material properties are shown in the following table. concrete shaping use the concrete damage model, prestressed steel strand applied prestress by cooling method, size is 1302MPa. Both ends of the steel strand binding with steel plate, in order to realize the restriction effect of prestress on the column bracket. The load size is $50 \mathrm{MPa}$, the displacement of the column surface constraint bracket in three directions. Unit size is $0.1 \mathrm{~m}$. Because this article mainly discusses stress state of the bracket column working under partial pressure, modeling of the middle column bracket.

Tab.1 form of material properties

\begin{tabular}{ccccc}
\hline & $\begin{array}{c}\text { Elastic } \\
\text { modulus } \\
\left(\mathrm{N} / \mathrm{mm}^{2}\right)\end{array}$ & Poisson's ratio & $\begin{array}{c}\text { Yield strength } \\
(\mathrm{MPa})\end{array}$ & $\begin{array}{c}\text { Linear } \\
\text { expansion } \\
\text { coefficient }\end{array}$ \\
\hline concrete & 32500 & 0.2 & & \\
\hline Steel plate & 210000 & 0.3 & & $1.2 \times 10^{-5}$ \\
\hline steel & 200000 & 0.3 & 400 & \\
\hline Steel strand & 200000 & 0.3 & 1860 & \\
\hline
\end{tabular}

\section{Calculation results and analysis}

The bracket and the reinforcement according to conventional calculation meet specification requirements, this paper in order to further explore the deep bracket in the change of external prestressing force area and position of the stress state. First, calculate stress the distribution of deep corbels in normal condition, Then in the calculation of the prestressed under the constraints of stress state and the stress cloud images are obtained, comparative analysis of the ultimate bearing capacity improvement.

\section{Calculation analysis of ultimate bearing capacity under normal working condition}

As shown below, they were reinforced and corbel the first principal stress nephogram and the third main stress nephogram. When a load is applied to 25.0561MPa, components are destroyed. First principal stress cloud of corbel can be seen, The maximum tensile stress in the middle corbel, The maximum tensile stress is 3.533Mpa which higher than concrete, at the same time, cracks appeared in the middle corbel ${ }^{[1]}$ where the steel began to bear the tensile stress.

Finally, when the tension steel reaches the yield stress, component is destroyed. At this time the maximum compressive stress located on the below Inclined plane of corbel, the size is $29.67 \mathrm{MPa}$, and it is not crushed. Combined with the bracket and the steel bar stress nephogram can be found, deep corbel in the normal working state as the same as general corbel can produce "tensile stress zone" and "pressure stress zone" ${ }^{[2]}$ in the same place with normal. This case was happened in the middle of corbel, in which the "tensile stress zone" and inclined plane of corbel vertical approximation, "Compression stress zone" along the loading position of the inclined to the column bottom bracket. Because of the middle corbel large height, The tensile area of concrete in middle of corbel is larger, therefore, the formation of "tensile stress zone" is wider than normal 


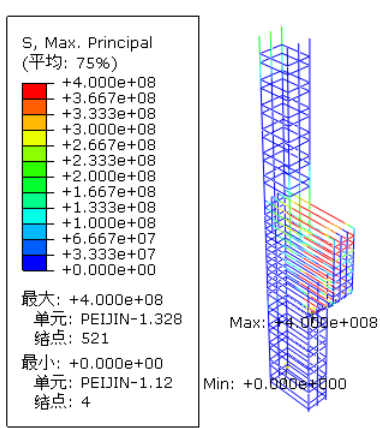

Fig-2 The first principal stress contour of rebar
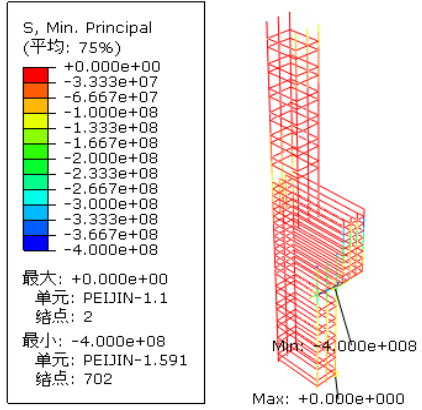

Fig-4 The third principal stress contour of rebar

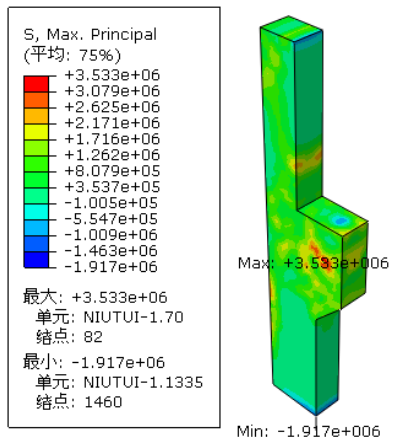

Fig-3 The first principal stress contour of corbel
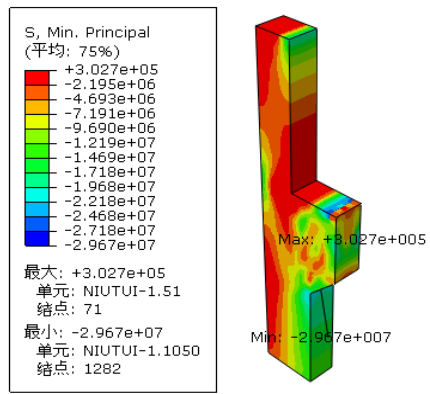

Fig-5 The third principal stress contour of corbel

\section{Calculation analysis of ultimate bearing capacity under the restriction of prestress}

Through the analysis on the stress of the normal working state of the above deep bracket to know tensile stress is large in middle of deep corbel which is Hazardous area. To offset part of tensile stress in the middle tension zone, applying prestress on the corbel side and making the concrete from the tension area is changed from one way to two way to improve the ultimate bearing capacity. The arrangement of 10 steel strand, 5 per side, vertical spacing $200 \mathrm{~mm}$, the applied prestress is $1302 \mathrm{MPa}$, Both ends of the plate size is $600 \times 1000 \times 20 \mathrm{~mm}$, The model shown below.

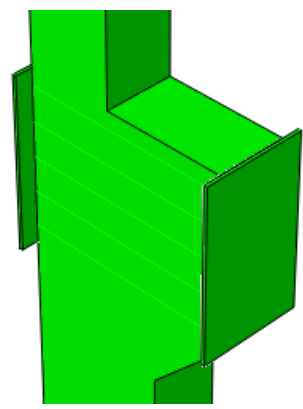

Fig-6 prestress location map of corbel

The results of the calculation of stress are shown in the diagram below, when the load is applied to the destruction of $40.163 \mathrm{MPa}$, the corbel is broken. So, Due to the effect of prestressed steel strand, deep corbel limit bearing capacity improved significantly by the original $25.056 \mathrm{MPa}$ increased to 40.163MPa. By the first principal stress cloud can be seen, The tension area of the reinforcement is mainly concentrated in the position which under the action of the load, The central area of corbel and under the position of the upper column. Combined with the first principal stress nephogram of steel and corbel can be seen, the tension zone of the concrete is still concentrated in the central region of the corbel and different from normal working state is that the central region of the concrete corbels bearing capacity and crack resistance is greatly strengthened due to the strong constraint of the prestressed steel strand. Because of the load position near the edge of the bracket, the load had a certain bending moment on the corbel, as a result the left most column bracket bear 
tensile stress. The first principal stress cloud of bar can be seen, the partial longitudinal stressed reinforcement of the left column under the corbel affected by tension which consistent with the place of maximum tensile stress of concrete. This shows that the concrete has been producing cracks and bar has been into the working state, but the damage area is located on the upper column and stirrup in this place is in tension yield leading to eventual destruction. Combined with the third principal stress cloud of steel and concrete images, concrete at load due to the restraint of the prestressing force to make it two way pressure greatly enhances the bearing capacity

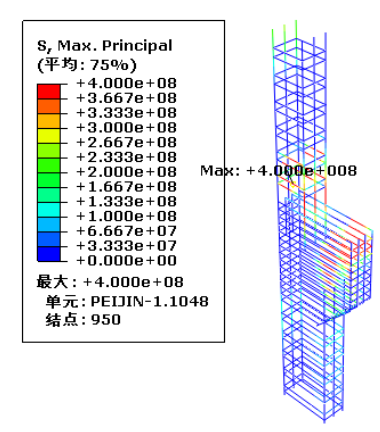

Fig-7 The first principal stress contour of rebar(prestress)
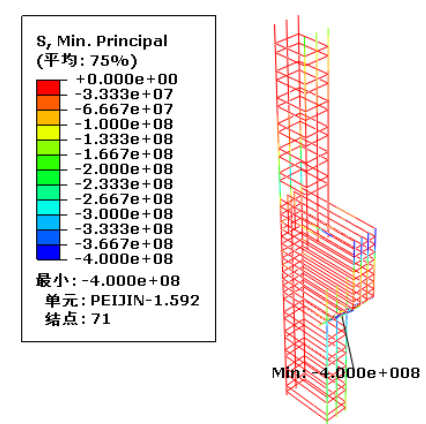

Fig-9 The first principal stress contour of rebar(prestress)

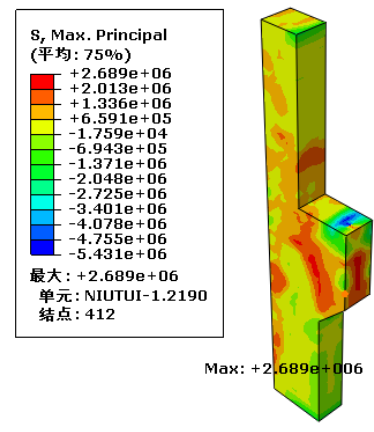

Fig-8 The first principal stress contour of corbel(prestress)
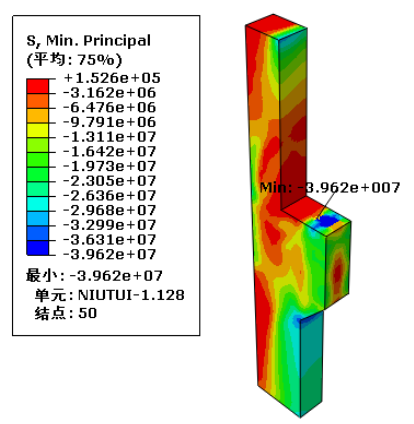

Fig-10 The first principal stress contour of corbel(prestress)

and the crack resistance. In addition, dangerous area of compression still under the Inclined plane of corbel and bear the pressure of the larger. The steel in this pace has been compression yield. But because of the concrete has not reached its ultimate compressive strength, here is not damaged.

Through the above analysis and combined with the actual situation can be found, It is not easy to achieve to applying prestress in the vertical one meter range of deep corbel, so the author calculate the steel plate of different size and different positions of the same area constraint on the middle part of the side corbel, The results of the statistics shown in the table below.

Tab.2 The influence of different applied area of prestress on the bearing capacity

\begin{tabular}{cccc}
\hline Plate size $(\mathrm{mm})$ & $\begin{array}{c}\text { Ultimate bearing } \\
\text { capacity }(\mathrm{MPa})\end{array}$ & $\begin{array}{c}\text { Enhance size } \\
(\mathrm{MPa})\end{array}$ & $\begin{array}{c}\text { Degree of } \\
\text { improvement }(\%)\end{array}$ \\
\hline $600 \times 400 \times 20$ & 30.809 & 5.249 & 23.0 \\
\hline $600 \times 600 \times 20$ & 35.73 & 10.674 & 42.6 \\
\hline $600 \times 800 \times 20$ & 37.792 & 12.736 & 50.8 \\
\hline $600 \times 1000 \times 20$ & 40.163 & 15.107 & 60.3 \\
\hline
\end{tabular}


Tab.3 600x400x20mm Steel plate in different position on bearing capacity of the statistics

\begin{tabular}{cccc}
\hline Position & $\begin{array}{c}\text { Ultimate bearing } \\
\text { capacity }(\mathrm{MPa})\end{array}$ & $\begin{array}{c}\text { Enhance size } \\
(\mathrm{MPa})\end{array}$ & $\begin{array}{c}\text { Degree of } \\
\text { improvement }(\%)\end{array}$ \\
\hline Upper part & 30.271 & 5.215 & 20.8 \\
\hline Middle part & 30.809 & 5.753 & 23.0 \\
\hline Lower part & 30.352 & 5.296 & 21.1 \\
\hline
\end{tabular}

Tab.4 600x600x20mm Steel plate in different position on bearing capacity of the statistics

\begin{tabular}{cccc}
\hline Position & $\begin{array}{c}\text { Ultimate bearing } \\
\text { capacity }(\mathrm{MPa})\end{array}$ & $\begin{array}{c}\text { Enhance size } \\
(\mathrm{MPa})\end{array}$ & $\begin{array}{c}\text { Degree of } \\
\text { improvement }(\%)\end{array}$ \\
\hline Upper part & 34.115 & 9.059 & 36.2 \\
\hline Middle part & 35.73 & 10.674 & 42.6 \\
\hline Lower part & 34.969 & 9.913 & 39.6 \\
\hline
\end{tabular}

Tab.5 600x800x20mm Steel plate in different position on bearing capacity of the statistics

Position Ultimate bearing Enhance size Degree of

\begin{tabular}{rccc} 
& capacity (MPa) & $($ MPa $)$ & improvement $(\%)$ \\
\hline Upper part & 37.402 & 12.346 & 49.3 \\
\hline Middle part & 37.792 & 12.736 & 50.8 \\
\hline Lower part & 36.406 & 11.35 & 45.3 \\
\hline
\end{tabular}

(Notes: "Upper part" is to put the upper edge of the steel plate and the edge of the corbel bearing surface together, "Middle part" is the steel plate is placed on the side of the center position of the corbel, "Lower part" is to put the lower edge of the steel plate and vertical edge corbel together)

The table above indicates that the increase in the area of the prestressing force and the increase of the bearing capacity are not linear increase. Considering the value of its ultimate bearing capacity and the degree of improvement, the use of steel plate with high $600 \mathrm{~mm}$ will have good effect. In addition, prestress position has little effect on enhancing the degree of bearing capacity of corbel. But, Constraint the middle place of corbel can improve its ultimate bearing capacity.

\section{Conclusions}

(1)Stress distribution of deep corbel under normal working condition as the same as normal, but on the bearing capacity, deep corbel stronger in ordinary bracket.

(2)Deep corbel changed its own state of stress under the restriction of the prestressing strand. Due to the strong restraint of prestress and the eccentricity of load, the left column concrete corbel crack in tension and stirrup reach yield strength leading corbel damaged.

(3)Corbel constrained by prestressed steel strand, the ultimate bearing capacity is not linearly with increase of area.

(4)When the prestressed constrained area determined, prestressed in different positions on the bracket will only slightly affect its ultimate bearing capacity. When prestressed force applied in the middle of corbels can increase its ultimate bearing capacity.

\section{Acknowledgements}

The selection of this thesis comes from the National Natural Science Foundation of China. The foundation number is $\mathbf{5 1 1 7 8 2 0 5 .}$

\section{References}

[1] Guo Jinshi, Zhuang Xinling. Design of reinforced concrete structures. Wuhan: Guo Jin, 2011.332-337

[2] Peng Rong. Structure and calculation of bracket. Railway Survey and Design.2008 (4): 104-109 